\title{
Género, desastres ambientales y consumo de agua embotellada. El caso de la cuenca del río Sonora
}

\section{Gender, Environmental Disasters, and Bottled Water Consumption: The Case of the Sonora River Watershed}

\author{
Verónica Vázquez-García* (D) http://orcid.org/0000-0002-0689-4397
}

\section{Resumen}

Objetivo: estudiar desde la perspectiva de género el consumo de agua embotellada en el contexto del desastre ambiental que provocó el derrame de $40000 \mathrm{~m}^{3}$ de lixiviados de cobre en el río Sonora. Metodología: se realizaron 40 entrevistas, un taller y se aplicaron 28 cuestionarios en distintas localidades de la cuenca. Resultados: el agua embotellada de distintas marcas y precios se ha convertido en un elemento de diferenciación entre las mujeres. Limitaciones: se requiere ampliar la muestra y realizar análisis biomédicos para profundizar en el estudio. Valor: se contribuye a explicar los factores que intervienen en la sustitución del agua de la llave por la embotellada en la cuenca del río Sonora. Conclusiones: el enfoque de género ayuda a entender las decisiones que toman las mujeres en relación con el agua para consumo humano.

Palabras clave: género; agua embotellada; distribución del agua; calidad del agua; derecho humano al agua.

\begin{abstract}
Objective: to study from a gender perspective the consumption of bottled water in the context of the environmental disaster caused by the spilled 40 ooo $\mathrm{m}^{3}$ of cupper leachates in the Sonora river. Methodology: 40 interviews, one workshop and 28 questionnaires were applied in various communities of the watershed. Results: bottled water of different brands and prizes has become an element of differentiation among women. Limitations: the need to broaden the sample and to conduct a biomedical analysis in order to deepen the results. Value: to explain the factors that intervene in the substitution of tapped water for bottled water in the Sonora watershed river. Conclusions: using a gender approach helps to understand the decisions that women make regarding water for human consumption.

Keywords: gender; bottled water; water distribution; water quality; human right to water.
\end{abstract}

Cómo citar:Vázquez-García, V. (202I). Género, desastres ambientales y consumo de agua embotellada. El caso de la cuenca del río Sonora. región y sociedad, el 473. doi: 10.22198/rys2021/33/I473

*Colegio de Postgraduados, Programa de Estudios en Desarrollo Rural, Campus Montecillo. Carretera Federal México-Texcoco Km. 36.5, Montecillo, Texcoco, México. Correo electrónico: vvazquez@colpos.mx

Recibido: 12 de abril de 2021

Aceptado: 18 de junio de 2021

Liberado: 19 de agosto de 2021

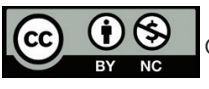




\section{Introducción}

México se ha convertido en el mayor consumidor de agua embotellada del mundo (sobre todo de garrafones de 20 litros de las marcas E-pura, Pureza y Ciel). Entre 2008 y 2018 su valor de mercado se disparó 152\%, pasando de 2671 a 6734 millones de dólares estadounidenses (Vega-Amaya, 2020). En la actualidad, el consumo anual de agua embotellada fluctúa entre 169 y 234 litros (l) por habitante, y los hogares gastan un promedio de 135 pesos mensuales en agua (Delgado-Ramos y Ávila-Calero, 2014), con importantes diferencias regionales (230 pesos en la Ciudad de México y 163 en Hermosillo). En esas dos ciudades, el gasto en agua embotellada rebasa las cuotas que se pagan por el servicio de agua potable. Además, en las alcaldías más pobres de la Ciudad de México, lo erogado en agua embotellada supera lo que la Organización de Naciones Unidas estipula como adecuado para la compra de dicho producto (3\% del gasto mensual de cada hogar) (Estrada-Vivas, 2016; Montero-Contreras, 2016).

Montero-Contreras (2006 y 2016) atribuye el incremento a diversas causas. Una de ellas es la privatización del servicio del agua a través de concesiones a particulares, situación que ha ocasionado el retiro del Estado de sus obligaciones fundamentales de suministrar agua potable. Delgado-Ramos (2014) y Delgado-Ramos y Ávila-Calero (2014) resaltan las deficiencias en este servicio, ya sea privado o público, en contraposición con las facilidades de portabilidad que ofrece el agua embotellada de Coca Cola, PepsiCo, Danone y Nestlé, empresas que acaparan $82 \%$ del mercado. Pacheco-Vega (2015) señala que la mercadotecnia se utiliza para transformar la percepción de la ciudadanía sobre la calidad del agua de grifo, lo cual las instancias encargadas de proveerla han sido incapaces de revertir. A este panorama hay que agregar el terremoto de 1985, la epidemia de cólera de la década de 1990 y la apertura comercial ocurrida en esa misma década que dio fin al modelo de sustitución de importaciones y favoreció la mercantilización del recurso (Pacheco-Vega, 2017).

Los estudios que se han citado hablan del creciente consumo de agua embotellada en México. Sin embargo, una de sus principales limitaciones es la ausencia de la perspectiva de género. En su discusión sobre el consumo nacional per cápita de agua embotellada, Pacheco-Vega (2015) no se adentra en las posibles diferencias por género, posición económica, edad o lugar de residencia. Delgado-Ramos (2015) hace el mismo ejercicio en una sola entidad, la Ciudad de México, y omite los mismos rubros. Montero-Contreras (2006) examina los distintos segmentos del mercado (agua simple, mineral y aromatizada) sin explorar las distintas preferencias entre los consumidores. Estrada-Vivas (2016) incluso señala que ciertas marcas se promueven como ayuda para adelgazar, pero no se pregunta sobre las personas a las cuales está dirigida esta publicidad. La ausencia de un enfoque de género obliga a preguntarse lo siguiente: ¿cómo han experimentado las mujeres la sustitución del agua del grifo por la embotellada?, ¿por qué sustituyen el agua del grifo por agua embotellada?, ¿qué implicaciones tiene para las de la tercera edad la portabilidad del agua embotellada, dado que los garrafones de 20 litros requieren fuerza física para ser manipulados?, ¿qué representa para la economía de las mujeres de escasos recursos el gasto 
de dicho producto?, ¿cómo lidian ellas con los desastres ambientales que provocan problemas de escasez y de contaminación del agua?

El presente artículo responde algunas de estas interrogantes en el contexto del desastre que causó el derrame de 40000 metros cúbicos $\left(\mathrm{m}^{3}\right)$ de lixiviados de cobre ocurrido el 6 de agosto de 2014 en las aguas del río Sonora. Los pozos se cerraron durante tres meses para determinar la gravedad del daño, y seis años después de su reapertura persisten las dudas sobre la calidad del agua que abastecen. El derrame vuelve aún más complejo el tema y pocos estudios han explorado el vínculo entre los desastres ambientales y el consumo de agua embotellada, aunque el de Pacheco-Vega (2019a) ha señalado que las autoridades gubernamentales tienden a dejar en manos de los consumidores (sin distinciones de género) los riesgos de salud y que las empresas aprovechan este vacío de poder para arraigar el consumo de agua embotellada entre la población. El artículo argumenta que dicho producto se ha convertido en un elemento de diferenciación entre las mujeres. Trabajar con perspectiva de género ayuda a entender que lo que en realidad está ocurriendo no es sólo la sustitución del agua del grifo por la embotellada, sino que también hay un uso diferenciado de los distintos tipos de agua en función de la posición económica y la edad de las mujeres.

\section{Propuesta conceptual: de la ecología política del agua a la ecología política feminista del agua}

La ecología política es una disciplina híbrida que integra el estudio de la naturaleza en su interacción con la sociedad, poniendo particular énfasis en los procesos de apropiación y de regulación que transforman el medio ambiente a través de normas e instituciones. El cambio socioeconómico influye en el ambiental, y viceversa, de manera que tanto la sociedad como la propia naturaleza regulan los recursos naturales. Desde esta perspectiva, la privatización del agua es una forma de regulación ambiental que consiste en transferir del sector público al privado la gestión del agua (Bakker, 2003). En el caso de México, la transferencia se expresa a través de concesiones al sector privado para surtir agua a ciudades y municipios, proceso que Ávila (2018) denomina "la neoliberalización del agua". En términos generales, los organismos que dan el servicio de agua, ya sean públicos o privados, carecen de los recursos necesarios para modernizar su infraestructura y mejorar la calidad del servicio (Vázquez y Sosa, 2017).

Hay dos temas que deben ser tratados para analizar la transferencia de la gestión del agua del sector público al privado: la distribución y la calidad. Ambos se asocian con el crecimiento urbano y la industrialización, que conduce a que el sector privado acapare el agua y la contamine con desechos industriales. La disponibilidad alude a la cobertura, al abastecimiento y a la cantidad de agua que debe suministrarse a cada vivienda. Una buena disponibilidad significa que el servicio es regular, continuo y suficiente. La calidad se refiere a la potabilidad del agua, que con frecuencia se ve comprometida por la contaminación 
biológica (microorganismos infecciosos) o química (sustancias tóxicas y radioactividad). La ecología política ayuda a determinar quiénes son los ganadores y quiénes los perdedores con respecto a la regulación del agua en referencia a su disponibilidad y calidad, y da a conocer el impacto diferenciado de la privatización en grupos sociales con distintos niveles de poder (Bakker, 2003).

Otra forma de privatizar el agua es convertirla en una mercancía intercambiable, envasable, empaquetable, sometida a las leyes de la oferta y la demanda y a la competencia, cuya distribución en botella conduce a la acumulación de capital en manos privadas. La mercadotecnia comercializa agua de distintos orígenes, tratamientos y formas de envasado como superiores o especiales dentro de un débil marco institucional que se muestra incapaz de promover el agua del grifo como apta para consumo humano (Pacheco-Vega, 2019b).

La privatización del agua, ya sea a través de concesiones a particulares o por medio del embotellamiento, tiene importantes consecuencias para las mujeres. La ecología política feminista (EPF) ayuda a profundizar en ellas. A diferencia de la ecología política, que sólo distingue a los actores sociales en función de sus diferencias de poder, la EPF retoma el concepto de interseccionalidad que propone la feminista negra Kimberlé Crenshaw (1989) ${ }^{1}$ para entender que las categorías de diferenciación, tales como el género, la posición económica o la edad, configuran diversas experiencias en la vida de las mujeres. Las diferencias se analizan en tres ámbitos: 1) saberes ambientales; 2) derechos y responsabilidades en relación con la propiedad y el acceso a los recursos naturales; y 3) participación femenina en los movimientos ecologistas (Rocheleau, Thomas-Slayter y Wangari, 1996). Elmhirst (2018) reformula y amplía dichos ámbitos de la siguiente manera: a) a los saberes ambientales agrega los conocimientos situados de manera específica en las experiencias de los grupos marginados o invisibilizados que desafían la universalidad del conocimiento; $b$ ) al acceso a los recursos añade el despojo de éstos; c) incluye las dimensiones emocionales, afectivas y corporales relacionadas con dichos recursos a escalas más íntimas; d) utiliza la ética feminista, el buen vivir y la sostenibilidad de la vida como estrategias de resistencia según los trabajos de Agenjo (2013) y Carrasco (2003).

En el caso específico del agua, Cancino y Cruz (2017), Priego y Soares (2017), Red de Género y Medio Ambiente (2006), Soares (2007) y Vázquez (2008) han subrayado la importancia de estudiar la división genérica del trabajo que asigna a las mujeres la responsabilidad de sostener la vida mediante labores de cuidado no pagadas, y a los hombres el papel de proveedores en la esfera de producción mercantil, que es la única valorada. Cuando hay falta de disponibilidad o contaminación del agua, las mujeres deben resolver los problemas con los medios al alcance, ya que rara vez tienen poder de decisión en los organismos operadores del agua o en otras estructuras comunitarias que se encargan de la gestión de

"La discriminación, como el tráfico en una intersección, puede fluir en una dirección y también en la otra. Si se presenta un accidente en una intersección, puede haber sido causado por autos transitando en cualquier dirección y, en ocasiones, en todas ellas. De la misma manera, cuando una mujer negra es lastimada porque se encuentra en una intersección, sus heridas pueden ser producto de la discriminación sexual o de la discriminación racial." (Crenshaw, 1989, p. 149; traducción de la autora.) 
ésta. Las mujeres alimentan a la familia, la visten y la protegen del frío y de las enfermedades. Además, dan cariño, transmiten seguridad y enseñan a vivir en comunidad (Agenjo, 2013; Carrasco, 2003). Pero la escasez o la mala calidad del agua afectan su capacidad de hacerlo y les provocan problemas de salud, lo que pone en riesgo la sostenibilidad de la vida de la sociedad entera.

En contextos mineros esos problemas se agudizan debido a las grandes cantidades de agua que se utiliza para separar metales y a la contaminación que éstos producen. Por citar algunos ejemplos, la empresa Goldcorp en Mazapil, en el estado de Zacatecas, utiliza 35 millones de litros de agua para procesar 130000 toneladas de material, lo cual compromete la capacidad de recarga de los acuíferos. Dicho estado se caracteriza por la polución generalizada de fuentes de agua a causa de los residuos mineros e industriales. Para las zacatecanas, eso representa mayores dificultades para producir alimentos y sus propios ingresos, situación que causa su desempoderamiento (Castro, Zapata, Pérez y Martínez, 2015).

Otro conocido sitio minero es el cerro de San Pedro, en San Luis Potosí. Ahí también se reportan problemas de escasez de agua. Una empresa la reparte en pipas y las mujeres deben invertir en recipientes para almacenarla, lo cual debilita aún más su poder de decisión sobre el recurso (Cortés, Zapata, Ayala, Rosas y Navarro, 2017). En pocas palabras, cuando el agua escasea o está contaminada, la vida de las mujeres se complica y su estatus social se deteriora. Por esa razón, el tratado internacional de Convención sobre la Eliminación de Todas las Formas de Discriminación en Contra de la Mujer (CEDAW por sus siglas en inglés) ha insistido en la importancia que tiene garantizar el derecho de las mujeres a una vivienda digna, a servicios sanitarios y al abastecimiento de agua. El acceso a ésta en cantidad suficiente y calidad adecuada es indispensable para mejorar los medios de vida, la seguridad alimentaria, la salud y el derecho a la vida digna de las mujeres (Programa de Naciones Unidas para el Desarrollo [PNUD], 2006).

Este artículo adopta el enfoque de la EPF para explorar el proceso de diferenciación de las mujeres en torno a la compra del agua embotellada en un contexto de desastre, como lo fue el derrame de la mina Buenavista del Cobre. El argumento central es que, por problemas de distribución y de calidad, el consumo de agua embotellada de distintas marcas y precios se ha convertido en un factor diferenciador social en la cuenca, y las mujeres dejan de ser ciudadanas con derecho al agua para convertirse en consumidoras cuyo elemento distintivo está en su posibilidad de adquirirla.

\section{Zona de trabajo y metodología}

La mina Buenavista del Cobre se estableció en Cananea en 1899 bajo el nombre de The Cananea Consolidated Copper Company, Sociedad Anónima (S. A.). En 1906 se convirtió en la empresa minera más grande y próspera de México (Bracamonte, Lara y Borbón, 1997). En 1971, la mitad de la empresa pasó a ser mexicana bajo el nombre de Compañía Minera de Cananea, S. A. de Capital 
Variable (C. V.) (Toscana y Hernández, 2017). A finales de la década de 1980, el gobierno de Carlos Salinas de Gortari privatizó el sector minero y Jorge Larrea adquirió la empresa. Su hijo, Germán Larrea Mota Velasco (Sariego, 2010), es el actual dueño. La mina todavía conserva una de las mayores reservas de cobre del mundo. En 2019 produjo 338000 toneladas (Cámara Minera de México [CAMIMEX], 2019).

La mina opera con un sistema de lixiviación compuesto por dos represas (Tinaja 1 y Tinaja 2). El 6 de agosto de 2014 se detectó una fuga en una de las cortinas de Tinaja 1. Se presume que fue ocasionada por la elevación de los niveles hidrostáticos de la solución de lixiviados de cobre y por un volumen considerable de agua de lluvia. Dicha solución se desplazó a lo largo de 270 kilómetros hasta la presa El Molinito, que abastece la ciudad de Hermosillo. El 12 de agosto la empresa dio aviso formal del desastre a la Procuraduría Federal de Protección al Ambiente (PROFEPA) (Fideicomiso Río Sonora, s. f.).

Se catalogó el derrame como "el peor desastre ambiental en la historia" del sector minero en México (Alfie, 2015). Afectó el río Sonora, el arroyo Tinajas, el río Bacanuchi, la presa El Molinito y las actividades de 20227 habitantes de los municipios de Arizpe, Banámichi, Aconchi, Huépac, San Felipe de Jesús, Baviácora y Ures, de los cuales $48.02 \%$ son mujeres (véanse tabla 1 y figura 1 ). El desastre ocasionó pérdidas económicas entre ganaderos y agricultores, daños a la salud de al menos 624 personas, la reactivación del conflicto entre la Sección 65 del Sindicato Minero Nacional y el Grupo México y la percepción colectiva de que "el río está muerto" (Luque y Murphy, 2020; Toscana y Hernández, 2017, pp. 3-4).

Tabla 1. Población afectada por el derrame

\begin{tabular}{|c|c|c|c|}
\hline Municipio & $\begin{array}{c}\text { Población } \\
\text { (número de habitantes) }\end{array}$ & $\begin{array}{c}\text { Mujeres } \\
\text { (porcentaje) }\end{array}$ & $\begin{array}{c}\text { Hombres } \\
\text { (porcentaje) }\end{array}$ \\
\hline Arizpe & 2788 & 48.13 & 51.87 \\
\hline Banámichi & 1825 & 49.37 & 50.63 \\
\hline Aconchi & 2563 & 47.87 & 52.13 \\
\hline Huépac & 943 & 47.61 & 52.39 \\
\hline San Felipe de Jesús & 369 & 45.53 & 54.47 \\
\hline Baviácora & 3191 & 47.92 & 52.08 \\
\hline Ures & 8548 & 47.93 & 52.07 \\
\hline Total & 20227 & 48.02 & 51.98 \\
\hline
\end{tabular}

Fuente: elaboración propia con datos del Instituto Nacional de Estadística y Geografía (INEGI) (2020).

Las actividades de la mina se suspendieron después del derrame y se multó a la empresa con 23 millones de pesos. Poco después se creó el Fideicomiso Río Sonora (FRS), cuyas acciones más importantes fueron las siguientes: la atención médica a 10875 personas, el seguimiento especializado a 358 personas 
con síntomas de intoxicación por metales pesados, la entrega de 27111 apoyos económicos como resarcimiento por desabasto de agua, daños a la salud y actividades agropecuarias y comerciales, la rehabilitación de 41 pozos, la instalación de 10188 tinacos en casas y edificios de interés comunitario, la creación de la Unidad de Vigilancia Epidemiológica y Ambiental de Sonora (Secretaría de Medio Ambiente y Recursos Naturales [SEMARNAT], 2018).

Figura 1. Cuenca del río Sonora

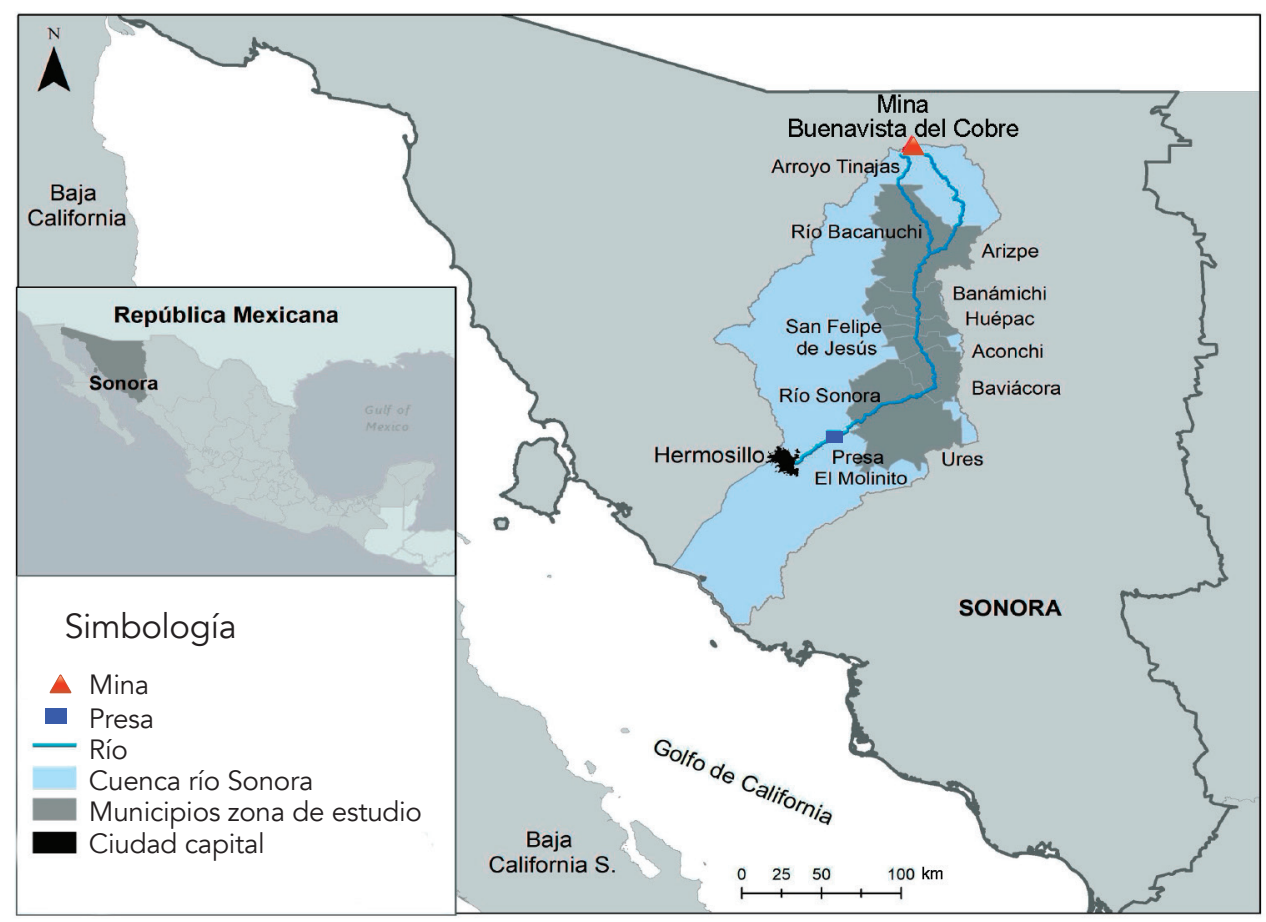

Fuente: elaboración de Rocío Martínez González con base en la red hidrográfica, escala 1:50 000 (INEGI, 2010).

Las labores del FRS se dieron por concluidas en febrero de 2017. Analizar sus alcances rebasa los objetivos de este artículo. Baste decir que la contaminación de las aguas del río se ha considerado un problema a largo plazo, persistente y riesgoso para la salud. El examen químico del agua confirmó la presencia de una solución ácida ferro-cuprífera con un potencial de hidrógeno $(\mathrm{pH})<3$, alta concentración de sulfatos y conductividad eléctrica $(C E)>5000$ micro Siemens por centímetro $(\mu \mathrm{S} / \mathrm{cm})$. Sus componentes principales son hierro $(\mathrm{Fe})$, aluminio $(\mathrm{Al})$, cobre $(\mathrm{Cu})$, manganeso $(\mathrm{Mn})$, cinc $(\mathrm{Zn})$, arsénico $(\mathrm{As})$, níquel $(\mathrm{Ni})$, cadmio $(\mathrm{Cd})$, plomo $(\mathrm{Pb})$ y cromo $(\mathrm{Cr})$ (Gutiérrez y Romero, 2015). Romero-Lázaro, Ramos-Pérez, Romero y Sedov (2019) estimaron una masa de 74.8 toneladas de metales (fierro, aluminio, magnesio y cinc) aportados al ecosistema por este derrame. En concentraciones altas, esos metales pueden acarrear graves pro- 
blemas de salud que son largos de explicar aquí, pero que se pueden consultar en las obras del Laboratorio Nacional de Geoquímica y Mineralogía LANGEM (2014), en Carabantes y Fernicola (2003) y en Rodríguez-Heredia (2017). Ibarra y Moreno (2017), Luque, Murphy, Jones, Búrquez, Martínez, Manrique y Esquer (2019), Luque y Murphy (2020) y Toscana y Hernández (2017) coindicen en que el protocolo de emergencia fue insuficiente, y sostienen que el derrame representa un claro caso de injusticia ambiental y de violación de los derechos humanos.

El enfoque de este artículo son los impactos del derrame en las actividades de las mujeres que tienen que ver con el sostenimiento de la vida. La EPF propone métodos horizontales de construcción del conocimiento que dan voz a las mujeres y a otros grupos marginados (Elmhirst, 2015). El análisis de sus experiencias en un contexto de desastre es fundamental para entender las dimensiones de género en la privatización del agua. La investigación priorizó ese enfoque utilizando fuentes secundarias, el trabajo etnográfico y una encuesta exploratoria.

El trabajo de campo tuvo dos fases. La primera se realizó durante febrero de 2020 y consistió en entrevistas individuales y grupales a personas del sector académico, minero y de la sociedad civil. Se seleccionaron por su conocimiento del tema, ya fuera por ser especialistas o por ser activistas. Entre las instituciones representadas se encuentran El Colegio de Sonora, la Universidad de Sonora, la Sección 65 del Sindicato Minero Nacional, el Clúster Minero de Sonora, Asociación Civil (A. C.), los Comités de Cuenca Río Sonora, la Red Fronteriza de Salud y Ambiente y el Frente Río Sonora. También se entrevistaron a algunos habitantes de los siete municipios afectados, entre ellos el director de Aguas (San Felipe de Jesús), el regidor de Obras (Aconchi), la tesorera del Comité de Agua Potable (Puerta del Sol, Ures), el operador de la bomba de agua potable (Baviácora) y el cronista de la ciudad (Banámichi). Los demás son ciudadanos de ambos sexos sin ningún cargo que quisieron colaborar con el proyecto. Las entrevistas se centraron en las formas de abastecimiento de agua, las experiencias con el derrame, las movilizaciones para lograr un justo resarcimiento por el daño, las compensaciones que recibieron del FRS, la problemática actual de la escasez y la contaminación del líquido y los roles de género relacionados con su aprovisionamiento. Cuando fue posible, se grabó la información y después se transcribió. El material resultante se codificó con la ayuda del programa Atlas Ti para ubicar las principales preocupaciones de las personas entrevistadas. Al final de las entrevistas, con mayor conocimiento del tema, se realizó un taller en la cabecera municipal de Ures, al cual asistieron cerca de diez personas. En él se presentaron los resultados preliminares de las entrevistas y se llevó a cabo la dinámica La Ruta del Agua (Coalición de Organizaciones Mexicanas por el Derecho del Agua [COMDA], 2017) con el objetivo de presentar problemas y encontrar soluciones para el abastecimiento y la calidad del agua. En esta fase de la investigación participaron 36 mujeres y 20 hombres.

La segunda fase del trabajo de campo tuvo lugar en octubre de 2020, cuando se aplicaron 28 cuestionarios que se repartieron de forma proporcional en tres comisarías ubicadas en la cuenca alta (Sinoquipe, Arizpe), en la media 
(San José de Baviácora) y en la baja (Puerta del Sol, Ures) del río Sonora. El cuestionario se aplicó sólo a mujeres y se diseñó después de haber analizado la información obtenida en la primera fase, con la finalidad de que fuera pertinente para la problemática que se identificó. El instrumento está compuesto de 101 preguntas cerradas, divididas en cuatro secciones: 1) datos generales de la mujer y su familia; 2) experiencias de empleo en el sector minero; 3) gestión, escasez y contaminación del agua; 4) participación en las movilizaciones que se llevaron a cabo después del derrame, en las organizaciones involucradas y el tipo de demandas formuladas. La información se procesó en Excel con el objeto de obtener la estadística descriptiva (frecuencias y porcentajes).

La idea inicial era dar la misma prioridad al método etnográfico y a la encuesta, pero la pandemia inició justo después de la primera fase de trabajo de campo e impidió que la muestra se ampliara y que el análisis estadístico fuera más elaborado. En este artículo sólo se utiliza la información del cuestionario que se refiere a la contaminación del agua, por lo que la principal fuente primaria de información fueron las entrevistas y el taller. Los nombres que figuran en el documento son ficticios para garantizar el anonimato de los informantes, dado que en la zona se vive un conflicto de larga duración que por momentos ha resultado tenso para sus principales actores. ${ }^{2}$ La encuesta sirvió para definir las tendencias de interpretación dentro de un marco de diseño cualitativo (Morgan, 1998).

\section{Crisis en la gestión del agua y su impacto en las mujeres}

\section{Escasez del agua}

El cierre de los pozos durante tres meses implicó a su vez el cierre de algunas escuelas, por lo cual las mujeres se vieron en la necesidad de atender a sus hijos e hijas desde casa y sin agua: "CONAGUA dijo: cerramos pozos. Pues se cerraron las escuelas, y [...] ¿qué van a hacer todo este tiempo en sus casas con los niños?" (Mercedes Barreto, Hermosillo, febrero de 2020). De las mujeres encuestadas, 68\% experimentó angustia por la falta de agua y enojo 40\%. Algunas desarrollaron problemas en la columna vertebral, en especial mujeres de la tercera edad con dificultades para manipular depósitos o recipientes:

Cómo nos hizo daño [...] llevando al sanitario el agua que teníamos que usar, con una cubetita bañarnos. Nos quedamos sin agua, mucho daño nos hizo. Yo me enfermé. Yo le atribuyo, y el doctor también, me salió un tumor maligno en la vejiga. Decía que eran los ácidos que venían en el agua, la contaminación, y era maligno el tumor. Me lo quitó. Me dieron quimioterapias. (Dulce Flores, Banámichi, febrero de 2020)

2 En el trabajo de campo colaboraron Tomás Ortega Ortega y Héctor Francisco Duarte Tagles. Dann Ojeda Gutiérrez y Rocío Martínez González transcribieron las entrevistas. 
Se llenaba nada más la pila de donde lavo, para llenar la lavadora y trastes, y así. Yo, para lavar y regar mis matas, batallamos mucho [...]. [Desde entonces tengo] desviadita la hernia. Me dijeron los doctores que sí me la podían arreglar [...]. A mí se me hace que era porque yo acarreaba agua en trastecitos para el baño, para bañarme [...]. Cuando siento que me molesta, me hago un té. Eso es mi único pendiente. (Eva Gutiérrez, La Estancia, Aconchi, febrero de 2020)

A mí me operaron de la matriz [...] luego me enfermé y también empecé con los mentados divertículos, y luego con los quistes en los riñones, que la presión. También, de andar con las mentadas cubetas se me descompuso la columna vertebral. (Esmeralda Gómez, San José de Baviácora, febrero de 2020)

Los primeros meses fueron fatales. Muy difícil para nosotros. Teníamos una hilera de un árbol que se llama sicomoro. Era un sombrío precioso aquí [en] el patio y le daba sombra a toda la casa. Se nos secaron porque no podíamos andar acarreando. Nos daban una barrica en el día, y pasaba la pipa y nos llenaba una, doscientos litros que usábamos para el inodoro, para bañarnos, trastes, ropa. (Catalina Peralta, Sinoquipe, Arizpe, febrero de 2020)

Seis años después del derrame, la escasez de agua continuaba presentándose. Todas las mujeres a quienes se entrevistó dijeron que la red que administran los Organismos Operadores de Agua (OOA) surte de ésta a su vivienda. A esas instancias se las conoce en la localidad como Organismo Operador Municipal de Agua Potable, Alcantarillado y Saneamiento (OOMAPAS). De ellas, 86\% refirió padecer cortes en el abastecimiento de agua: "luego nos apagan la bomba [...] y ya no tenemos agua [...] si mandan cerrar la llave, la misma gente la vuelve a poner y la abre" (Emilia, La Estancia, Aconchi, febrero de 2020). En la cabecera municipal de Ures se registró el mismo fenómeno: "a cada rato cortan el agua porque se reventaron tubos o algo" (María López, Ures, febrero de 2020).

Calificó de "bueno" el servicio del OOMAPAS 33\%. En promedio pagan 130 pesos mensuales, cantidad cercana a la que se paga en la Ciudad de México (150 pesos) (Montero-Contreras, 2016). Considera que este precio es justo 46\%; $39 \%$ lo considera alto o muy alto y justifica su respuesta con relatos sobre las deficiencias. Algunas incluso, en protesta, han dejado de pagar:

Hay mucha gente que dice: "Yo, desde la contaminación, no pago el agua [...] porque no es justo, estamos comprando agua [...]”. Yo sí la pago, porque hace falta para bañarse, para las plantas, para lavar y todo. Se imagina si no tuviéramos esta [...] mala agua, qué haríamos. Ni modo. (Esmeralda Gómez, San José de Baviácora, febrero de 2020)

El regidor de obras de Aconchi dijo que la situación en que se encuentran los OOMAPAS es bastante complicada. En su municipio no hay recursos para reemplazar las "mangueras de muy mala calidad", situación que ocasiona descomposturas "casi a diario". La gente afectada exige atención a toda costa, pero 
no está al corriente en sus pagos: "El otro día un señor me quebró un tubo [...] primero voy a checar tus impuestos y tu recibo del agua. Debía siete mil pesos y todavía la estaba haciendo de tos" (Pedro Méndez, Aconchi, febrero de 2020). El único municipio que reporta niveles bajos de morosidad es San Felipe de Jesús, y su capacidad para resolver problemas de tuberías rotas es de "cuarenta y ocho horas" (Rafael Ballesteros, encargado de la oficina de Aguas, San Felipe de Jesús, febrero de 2020). Éste es uno de los pocos municipios que cuenta con un pozo nuevo, aunque hay quien dice que su ubicación es incorrecta porque se encuentra en una zona donde hasta hace poco había actividad minera.

Contaminación química del agua

De las mujeres encuestadas, $71 \%$ considera que el agua de la red está contaminada. En relación con su papel de principales encargadas de sostener la vida, $70 \%$ estuvo de acuerdo o totalmente de acuerdo con la siguiente afirmación: "Me estreso al pensar en la contaminación de la fuente de agua que me abastece". He aquí algunos testimonios:

En los primeros tiempos no dormía, no dormía nada [...]. Yo me sentaba en la madrugada a llorar [...]. El plomo poco a poco se va apoderando del cuerpo [y] [...] va a ocasionar problemas de conducta, va a tener un deterioro cognitivo el niño, junto con el aluminio, tantito peor. (Maricela Ventura, Baviácora, febrero de 2020)

Pasan desechos de ellos, que atraviesan La Mora, van y desembocan directamente al río [...]. Yo ya voy a cumplir en este mes sesenta y dos años. Jamás me hubiera imaginado que iba a andar en éstas, ahí, en medio, sufriendo. Que te hagan sufrir tanto. (Maricela Ventura, Baviácora, febrero de 2020)

En cuanto a los padecimientos físicos asociados con la mala calidad del agua, $61 \%$ reportó tener alguno. Los más frecuentes son los cutáneos y los gastrointestinales. Los trabajos de Castro et al. (2015), Salazar y Rodríguez (2015), Cortés et al. (2017) y Dani, Malavolta, Santos, Serrano-Neves y Terrier (2019) realizados en contextos mineros reportan problemas similares. Las mujeres atribuyen la contaminación del agua a la actividad minera en $95 \%$, a las descargas de drenaje en $55 \%$, a la falta de mantenimiento de la red en $55 \%$, al uso de agroquímicos en $50 \%$ y a la producción animal en $45 \%$. A continuación se presenta una opinión sobre la mina Buenavista del Cobre:

Aquí, que quiere un agricultor abrir un pozo, se la hacen de mucha bronca. No hay permiso. No esto; no lo otro. Y la mina sí puede hacer lo que le dé la gana [...]. Una mina tiene cincuenta años de vigencia y con la oportunidad todavía [...] de otros cincuenta, cien años. ¿Nosotros cuándo vamos a durar cien años? [...]. La minería sí tiene mucho, mucho, mucho privilegio. (Esmeralda Gómez, San José de Baviácora, febrero de 2020) 
El Sistema Nacional de Información del Agua (SINA) (2015) reporta una cobertura nacional de agua potable de $95.31 \%$. Sonora presenta $97.56 \%$, con niveles un poco más bajos en zonas rurales 94.58\%). Sin embargo, los OOA del estado carecen de un sistema de gestión que dé a conocer los costos de operación y niveles de consumo de agua. Además, los organismos presentan morosidad considerable en los pagos (Comisión Estatal del Agua [CEA], 2016). A este panorama, generalizado en el país, hay que añadir los daños que causó el derrame. La población manifiesta la persistente desconfianza en la calidad del agua y se niega a cubrir las cuotas, situación que complica aún más la gestión del agua y las actividades de sostenimiento de la vida que realizan a diario las mujeres. Las experiencias que se han documentado en esta sección ayudan a dimensionar los impactos de género debidos a la crisis que ocasionó el derrame en la gestión del agua.

\section{Agua embotellada, producto que distingue a las mujeres}

Distintas aguas de garrafón

Según Luque et al. (2019), 26 meses después del derrame, 84\% de la población de la cuenca compraba agua embotellada. Los datos de la encuesta coinciden: $79 \%$ de las mujeres dijeron comprar el producto. El motivo principal es la desconfianza en el agua de la red, problema común en el país y también en la capital del estado, donde 96\% de la población la compra (Estrada-Vivas, 2016). No obstante, las mujeres de la cuenca marcaron "un antes y un después" en relación con el derrame que, según ellas, precipitó el cambio de hábitos: "los que vendían agua de garrafón, ahí namás estaba el negocio, hasta que ahora que ya se hizo un negociazo" (Maricela Ventura, Baviácora, febrero de 2020). Gloria García atribuye el crecimiento de este "negociazo" al "pánico" de la gente:

Cuando uno se da cuenta de esas cosas, uno vive con pánico, estrés y todo tipo de preocupaciones [...]. Desde que supe de eso de la contaminación, ahora la que consumo es [agua] E-pura. Es la que recomiendan y es la más cara, la trae la Pepsi Cola. Hay veces que traen carga de doscientos garrafones y se acaba luego luego, a pesar de ser tan cara. (Gloria García, Aconchi, febrero de 2020).

Lo importante es que no todas las mujeres pueden comprar agua embotellada de la misma calidad. En ese sentido, el agua (el recurso más básico para sostener la vida) se ha convertido en un elemento de diferenciación de posición económica y edad entre las mujeres. Es así que 70\% de las que consumen agua embotellada, la adquiere en pequeñas purificadoras, mientras que el restante $30 \%$ busca las marcas más comerciales en las tiendas Oxxo (E-pura, Pureza y Ciel) que no se envasan en la localidad. El que se adquiera agua de las pequeñas purificadores (más barato) y no de las marcas muestra la precariedad de la economía de la cuenca, dado que la tendencia nacional muestra lo contrario. 
Coca-Cola, Danone, Nestlé y PepsiCo concentran 70\% del mercado, mientras que $30 \%$ corresponde a las pequeñas purificadoras, que venden mucho más barato. Si se compara el comportamiento de los habitantes de la cuenca con el de los de la Ciudad de México, el primero se parece al de las alcaldías Tláhuac e Iztapalapa, que tienen los menores ingresos y donde las pequeñas purificadoras concentran 70.37 y $50.38 \%$ del mercado, respectivamente (Montero-Contreras, 2016).

El tema de la posible contaminación del agua embotellada ha sido poco tratado en la literatura, dando por un hecho que es adecuada para consumo humano. Ni el gobierno ni las organizaciones ambientalistas se han preocupado por monitorear la producción de marcas propias (Pacheco-Vega, 2017), a pesar de que la Procuraduría Federal del Consumidor no ha realizado pruebas de la calidad del agua embotellada desde 1997 (Estrada-Vivas, 2016). En la cuenca del río Sonora, $18 \%$ de las mujeres dijo que el agua de garrafón está contamina$\mathrm{da}$, y no fue posible distinguir si se referían a las pequeñas purificadoras o a las empresas transnacionales. Sus afirmaciones son difíciles de confirmar, puesto que no existe un proceso de monitoreo que certifique la calidad química y biológica del agua que comercializan las casi siete mil pequeñas purificadoras en todo México (Pacheco-Vega, 2015). En la cuenca, como en el resto del país, esas empresas utilizan el agua de la red y la distribuyen después de darle un tratamiento poco conocido por la población (Estrada-Vivas, 2016; Montero-Contreras, 2006; Vega-Amaya, 2020). Este problema se agrava en la cuenca porque la gente se conoce entre sí y por lo mismo no se atreve a denunciar los problemas de falta de calidad en el agua: "No crea que está muy purificada. No voy a decir quién, ni dónde, pero salió un garrafón mal, que el dueño se molestó con mi hermano” (Virginia Benítez, Ures, febrero de 2020). Así lo señaló Estela López:

Yo le compro a la purificadora de aquí [...] es la misma agua de los pozos. Sí quitan bacterias, eso nada más, pero no le quitan metales pesados porque no están capacitadas. Y los metales pesados se nos van directo, ni siquiera le sacan la vuelta. (Estela López, Banámichi, febrero de 2020)

El principal problema de salud, atribuible a la compra de agua embotellada y que no se reporta en ningún otro estudio, tiene que ver con el tamaño y el peso del garrafón. De las mujeres que consumen agua embotellada, $41 \%$ reportó malestares musculares y de la osamenta por ese motivo. Hay que cargar los garrafones, jalarlos, acomodarlos, y algunas mujeres son de edad avanzada:

Es un cansancio. Tengo miedo de que me vayan a fallar las rodillas. El del agua viene y me deja los garrafones aquí. Yo los tengo que poner más allá. Tengo una casa muy económica, muy chiquita. Los garrafones los pongo debajo de la mesa y también tengo que andar jalándolos, acomodándolos. (Gloria García, Aconchi, febrero de 2020)

Además, las mujeres que residen en algunas de las comisarías deben desplazarse a las cabeceras municipales para comprar agua, por lo general en el vehículo de su esposo, cuando éste tiene tiempo: 
Nunca han venido a repartir o a vender aquí. Se les hace muy distante, muy lejos. Como es la sierra, aunque está pavimentado, se les hace mucho el peso del agua y gastan mucha gasolina por los carros [...]. [Nosotros] vamos y la compramos en carro [...] mi esposo y yo. (Catalina Peralta, Sinoquipe, Arizpe, febrero de 2020)

La necesidad de desplazamiento asociada con la compra de agua embotellada es un problema que requiere mayor análisis, pues afecta a las mujeres pobres, a las de mayor edad y a las que viven en lugares alejados. En el estudio realizado por Vega-Amaya (2020) en Hermosillo, 61.8\% dijo tardar menos de quince minutos para trasladarse desde su casa hasta el lugar donde compra o rellena el garrafón, pero no hay datos fidedignos sobre las características de las personas que realizan este desplazamiento.

Distintos usos del agua según su fuente

Otro factor que distingue a las mujeres es el uso que le dan al agua del grifo versus al de la embotellada. El agua de la red es para regar plantas, lavar trastes, limpiar la casa, bañarse y consumo animal. El agua embotellada se usa para el consumo humano y para preparar alimentos. Pero 32\% de las mujeres dijeron que a veces usan agua de la llave para beber y $43 \%$ para preparar alimentos, lo que exhibe la precariedad de sus economías. He aquí algunos testimonios sobre el uso diferenciado del agua en función de las posibilidades económicas de las mujeres:

[El agua] de la llave, pues la uso a veces para regar las plantas, que ya no tengo porque se secaron también. Ésta [la de garrafón] es para lavar trastes. En veces lavo la verdura. (Gloria García, Aconchi, febrero de 2020)

El agua del tinaco no se puede usar para alimento pues. Para alimentación tienes que comprar agua de garrafones, porque el agua del tinaco no la puedes usar para agarrar un vaso y empinártelo. (Diana Carrasco, Mazocahui, Baviácora, febrero de 2020)

Además de la sustitución del agua del grifo por la embotellada, en la cuenca del río Sonora también se detectó la decisión consciente de las mujeres de usar el agua de la llave para algunas actividades y la de garrafón para otras. No es que las personas se contradigan, como señala Vega-Amaya (2020) en el estudio realizado en Hermosillo, Sonora: "los resultados [...] son un tanto contradictorios, ya que, aunque no se considera que el agua de la llave es apta para beber, casi el $50 \%$ sí la utiliza para preparar alimentos" (p. 90). Cuando se visibilizan las mujeres al centro del análisis, como las encargadas de sostener la vida, es posible notar que ellas toman difíciles decisiones en el ámbito del vacío institucional y en una situación económica precaria que las obliga a poner en riesgo su salud y la de sus familias. Siguiendo esta línea argumentativa, en la cuenca se identificaron tres grupos de mujeres cuyos rasgos distintivos fueron su ca- 
pacidad para adquirir agua embotellada de distinta calidad, y la función que le dan. El primer grupo incluye a las mujeres que no tienen recursos económicos para consumir agua embotellada y utilizan la de la llave para todos los usos:

Algunos, por cara, no la usan [el agua de garrafón]. Un día estaba yo en una casa y le dije a la señora, oiga, su hijo quiere tomar agua de la llave. Me dijo, de ahí tomamos [...] si compro agua, no les doy comida. No me alcanza para los frijoles, no me alcanza para darles de comer si me pongo a comprar agua. (Gloria García, Aconchi, febrero de 2020)

Una de las entrevistadas padece frecuentes cortes en el servicio de la red, por lo que su esposo acude a un pozo de riego para acarrear agua que ambos tienen que filtrar antes de poderla usar:

Para bañarnos, usamos la del pozo. La colamos, le sale un sedimento amarillo. Que yo, cuando riego, trato de limpiarlo para las milpas, y la meneo con una cubeta, que se revuelva y la tiro, pero, no deja de salir. (Raymundo Medina, Sinoquipe, Arizpe, febrero de 2020)

El segundo grupo es el más numeroso. Incluye a las mujeres que sí adquieren agua embotellada, pero que se ven obligadas a racionarla en función de quien consumirá los alimentos:

Le tenemos desconfianza al agua [...]. Que viene gente, pues yo agarro agua del garrafón para no darles de ésa [...]. Una que otra comida, la hacemos con el agua de garrafones. Nos recomienda mucha gente que no tomemos agua porque la contaminación no se va a quitar nunca. (Luisa Santos, Mazocahui, Baviácora, febrero de 2020)

Algunas hacen esfuerzos adicionales para comprar agua embotellada:

Ahorita toda la gente tiene que hacerle la lucha para comprar el agua, porque no hay recursos. Esta señora de aquí, la viejita que le digo, vende jabón. Una hija le trae jabón de los trastes, le trae colores, cuadernos, cosas así. La mayoría de la gente es así. (Esmeralda Gómez, San José de Baviácora, febrero de 2020)

En el tercer grupo están las mujeres que tienen familia en Hermosillo y pueden adquirir agua allá: "diez galones a la semana, si no me alcanza, voy a Oxxo por Bonafont” (María Rodríguez, Ures, febrero de 2020). Este grupo también incluye a una mujer que compra toda el agua en Estados Unidos, porque viaja para allá y además desconfía de cualquier agua que se pueda adquirir en México:

Tenemos agua de garrafón, [pero] ¿cómo la limpiarán? ¿Cómo estará? No sé, yo mejor no la tomo. Yo tomo de botellita. Cuando vamos del otro lado, me traigo mis cajas de botellitas [en la cajuela del coche]. (Tania Durán, Banámichi, febrero de 2020) 
Las mujeres del tercer grupo son muy pocas. Tienen la posibilidad de usar agua embotellada no sólo para tomar, sino también para asearse: "para lavarme los dientes, tenemos unas botellitas de agua para el enjuague. Yo no me enjuago con agua de la llave" (Tania Durán, Banámichi, febrero de 2020). "Nos lavamos rápido, corriendo, nuestra cara y partes nobles y todo eso [con] agua purificada" (María Rodríguez, Ures, febrero de 2020). Una de las mujeres mencionó los supuestos beneficios asociados con el nivel de $\mathrm{pH}$ de ciertas marcas de agua: "la E-pura es la única que venden de Hermosillo que no tiene sales". Ella no puede adquirirla por falta de recursos: "es más caro el garrafón; a veces no hay [dinero] y entonces compro de la de aquí, de las purificadoras de aquí" (Estela López, Banámichi, febrero de 2020). Su situación ilustra una vez más la precaria situación económica en la que viven las mujeres de la cuenca, potenciada por la crisis en la gestión del agua que se agravó debido al derrame.

\section{Conclusiones}

En este artículo se propuso analizar el consumo de agua embotellada con perspectiva de género en un contexto de desastre. Se estudia el caso de la cuenca del río Sonora, que sufrió el peor desastre minero en la historia del país, según declaraciones oficiales. La minería a cielo abierto involucra la instalación de presas de lixiviación y residuos donde se acumulan los desechos tóxicos derivados de la separación de metales. La amplitud y la capacidad de las presas son un riesgo latente para el ambiente y la población debido a la acumulación de metales y a las posibles fracturas de su estructura. Los testimonios recabados en la cuenca revelan la presencia histórica de desfogues de la mina Buenavista del Cobre sobre el río Sonora, sin consecuencias aparentes. El derrame de agosto de 2014 produjo cambios bruscos en la distribución y en la calidad del agua, situación que incrementó la compra del agua embotellada.

El trabajo adopta la EPF para contribuir con información al análisis del consumo de agua embotellada en un contexto de desastre. Algunos trabajos previos han documentado las causas que obligan a la población, sin distinción de género, a comprar agua embotellada. También revisan el ritmo acelerado en el crecimiento de su consumo, el gasto per cápita en agua embotellada por hogar en el ámbito nacional y por localidad (Ciudad de México y Hermosillo) y las diferencias entre los niveles de gasto en una misma localidad, en este caso la Ciudad de México. La investigación enriquece esa literatura con los datos recabados de la experiencia de las mujeres rurales de la cuenca del río Sonora. A continuación, se discuten sus tres principales hallazgos y se reflexiona sobre sus implicaciones para el estudio del agua embotellada desde la óptica de la EPF.

1. Las experiencias recopiladas ponen de relieve la importancia de trascender los datos oficiales sobre la cobertura de agua entubada, con el fin de examinar las dinámicas locales de escasez y de contaminación de agua. La crisis en la gestión de los organismos operadores de agua está generalizada en el país, pero el derrame en la cuenca dificultó esa situación aún más, acrecentó la 
persistente desconfianza en la calidad del recurso y fomentó la renuencia de los usuarios a pagar el servicio. Las mujeres se estresan y se angustian por la crisis en la gestión del agua, pero no tienen los medios para canalizar su descontento, porque no forman parte de las instituciones que la administran. Para superar esta situación, es necesario buscar soluciones a partir de sus necesidades e incrementar su poder de decisión en estas instancias. La EPF fue en particular útil para detectar algunas de estas necesidades, así como la importancia de visibilizar sus experiencias.

2. La rentabilidad del negocio de agua embotellada en la cuenca del río Sonora ha provocado la segmentación del mercado para ofrecer dos tipos de agua: la que no se envasa en la localidad y la que sí. Al comparar esta situación con la de la Ciudad de México, la región de la cuenca se comporta como lo hacen las alcaldías más pobres de la ciudad, donde predomina la compra de agua embotellada a pequeñas purificadoras. No se está diciendo que la calidad del agua que venden estas empresas sea mala, sino que las mujeres desconocen cuál es. En el contexto del derrame, y puesto que dichas empresas se abastecen de los pozos afectados, dudar de su calidad es más que justificable. Hay que añadir los problemas sobre el uso de agua embotellada, poco discutidos en otros estudios, como el peso de los envases y la necesidad de tener un vehículo para trasladarse y comprarlos, lo que afecta a las mujeres pobres y de la tercera edad que residen en lugares alejados. El enfoque de interseccionalidad que ha propuesto la EPF fue muy útil para distinguir los procesos de diferenciación entre las mujeres a partir de su posición económica y edad.

3. El artículo ayuda a complejizar el análisis de la sustitución del agua del grifo por la embotellada. La EPF ayuda a visibilizar que las mujeres son las principales encargadas de sostener la vida. Mediante este enfoque, se documentaron las decisiones difíciles que deben tomar durante una crisis incrementada por el derrame. Un tercio de las mujeres siguen usando agua de la llave para beber; y poco menos de la mitad, para preparar alimentos. Las demás han dejado de usar la de la red y se han vuelto consumidoras de agua embotellada a pesar de su situación de precariedad económica. A veces tendrán el dinero para comprar agua embotellada, pero no el medio para trasladarse, o tendrán el dinero y el medio de transporte, pero no las condiciones físicas para cargar el envase. 0 tal vez no tendrán el dinero y se verán obligadas a consumir el agua de la llave. Su posición económica y su edad interactúan de forma permanente para definir las opciones que tienen para enfrentar el incremento de la crisis del agua ocasionado por el derrame.

Estos hallazgos ayudan a resaltar la importancia de adoptar enfoques como la EPF en el estudio del agua embotellada. No basta con decir que el incremento en el consumo se debe a la desconfianza en el agua de la llave o a la publicidad favorable al agua embotellada; tampoco con decir que dicho incremento está generalizado. El enfoque de género permite detectar las condiciones de vacío institucional y precariedad económica en el cual las mujeres toman decisiones 
referentes al consumo de agua. En la cuenca, las diferentes posiciones económicas y la edad de las mujeres segmentan el mercado. Los derechos al agua, a la salud y a una vida digna se vulneran más cuando las mujeres dejan de ser usuarias de la red y se convierten en consumidoras de un mercado segmentado en función del poder adquisitivo.

Entre los temas que este artículo deja pendientes, están el análisis cuantitativo de los cambios aquí mostrados a partir de muestras más amplias; obtener información sobre el gasto que eroga cada hogar en agua embotellada, quién lo hace, qué necesidades se sacrifican por esas decisiones y a quién le toca pagar por el sacrificio; evaluar la calidad del agua que surten las embotelladoras locales mediante análisis de laboratorio; dar seguimiento clínico a los problemas de salud que reportan las mujeres; y analizar el impacto ambiental por contaminación de botellas de agua.

\section{Referencias}

Alfie, M. (2015). Conflictos socio-ambientales: la minería en Wirikuta y Cananea. El Cotidiano (191), 97-108. Recuperado de http://www.redalyc.org/ articulo.oa?id=32538023011\%0ACómo

Agenjo, A. (2013). Economía femnista: los retos de la sostenibilidad de la vida. Revista Internacional de Pensamiento Político (8), 15-27. Recuperado de https: / / www.upo.es/revistas/index.php/ripp/article/view/3654

Ávila, P. (2018). El Estado y la cuestión del agua en el contexto de la mundialización. En A. Torres Rodríguez y E. Moral Pajares (eds.), Agua y ecología política en España y México (pp. 21-40). Guadalajara: Universidad de Guadalajara.

Bakker, K. J. (2003). A political ecology of water privatization. Studies in Political Economy 70(1), 35-58. doi: https://doi.org/10.1080/07078552.2003.1 1827129

Bracamonte, A., Lara, B. E., y Borbón, M. I. (1997). El desarrollo de la industria minera sonorense: el retorno a la producción de metales preciosos. región y sociedad, 8(13-14), 39-75. doi: https://doi.org/10.22198/rys.1997.13-14. a1136

Cámara Minera de México (CAMIMEX). (2019). Informe anual 2019. Ciudad de México: CAMIMEX. Recuperado de https://www.camimex.org.mx/files/4415/6262/3084/02_info_2019.pdf

Cancino, M. del S., y Cruz, E. (2017). Relaciones de poder e inequidad de género: Villahermosa Yalumá, Comitán, Chiapas. Iztapalapa. Revista de Ciencias Sociales y Humanidades (83), 139-163. doi: https://revistaiztapalapa.izt. uam. mx/index.php/izt/article/view/39/53

Carabantes, A. G., y Fernicola, N. (2003). Arsénico en el agua de bebida: un problema de salud pública. Revista Brasileira de Ciências Farmacêuticas 39(4), 365372. doi: https:// doi.org/10.1590/s1516-93322003000400003 
Carrasco, C. (2003). La sostenibilidad de la vida humana, ¿un asunto de mujeres? En M. León (comp.), Mujeres y trabajo: cambios impostergables (pp. 5-25). Porto Alegre: Veraz Comunicação.

Castro, A., Zapata, E., Pérez, M. A., y Martínez, B. G. (2015). Desposesión, minería y transformaciones en la vida de la población de Cedros, Zacatecas, México. Oxímora. Revista Internacional de Ética y Política (7), 276-299.

Coalición de Organizaciones Mexicanas por el Derecho del Agua (COMDA). (2017). Manual para taller en defensa del agua para promotoras y promotores. Ciudad de México: COMDA.

Comisión Estatal del Agua (CEA). (2016). Programa de mediano plazo 20162021. Hermosillo: CEA.

Cortés, R., Zapata, E., Ayala, C., Rosas, R., y Navarro, H. (2017). Megaminería y género. Acumulación por desposesión en Cerro de San Pedro, San Luis Potosí. Sociedad y Ambiente, 5(12), 61-97.

Crenshaw, K. (1989). Demarginalizing the intersection of race and sex: a black feminist critique of antidiscrimination doctrine, feminist theory and antiracist politics. University of Chicago Legal Forum (1), 139-167.

Dani, S., Malavolta, C., Santos, M. dos, Serrano-Neves, P., y Terrier, L. (2019). Geocide, ecocide, and genocidal type outcomes from large-scale open pit mountaintop gold mining in the outskirts of Paracatu, Brazil. Enviromental Justice, 12(3), 1-13. doi: https://doi.org/10.1089/env.2018.0039

Delgado-Ramos, G. (2014). El negocio de bebidas y agua enbotellada. En G. Delgado (ed.), Apropiación de agua, medio ambiente y obesidad. Los impactos del negocio de bebidas embotelladas en México (pp. 21-46). Ciudad de México: Centro de Investigaciones Interdisciplinarias en Ciencias y Humanidades, Universidad Nacional Autónoma de México.

Delgado-Ramos, G. (2015). Water and the political ecology of urban metabolism: The case of Mexico City. Journal of Political Ecology, 22(1), 98-114. doi: https://doi.org/10.2458/v22i1.21080

Delgado-Ramos, G., y Ávila-Calero, S. (2014). La industria embotelladora en México: negocio, regulación y apropiación del agua. En G. Delgado-Ramos (ed.), Apropiación de agua, medio ambiente y obesidad. Los impactos del negocio de bebidas embotelladas en México (pp. 57-66). Ciudad de México: Centro de Investigaciones Interdisciplinarias en Ciencias y Humanidades, Universidad Nacional Autónoma de México.

Elmhirst, R. (2015). Feminist political ecology. En S. MacGregor (ed.), The Routledge Handbook of Gender and Development (pp. 519-530). Nueva York: Routledge.

Elmhirst, R. (2018). Ecologías políticas feministas: perspectivas situadas y abordajes emergentes. Ecología Política, (54), 50-57. Recuperado de https:// www.ecologiapolitica.info/?p=10162

Estrada-Vivas, L. (2016). Los rostros del agua embotellada en México: ¿Por qué somos los mayores bebedores de este problema? Centro de Investigación y Docencia Económicas (60). Recuperado de http://repositorio-digital.cide. edu/handle/11651/584 
Fideicomiso Río Sonora. (s. f.). Resumen del libro blanco de las acciones y medidas de remiediación, reparación y/o compensación de los daños al ambiente y a la salud generados por el derrame en los ríos Bacanuchi y Sonora. Recuperado de http://www.fideicomisoriosonora.gob.mx/docs/Resumen\%20 Libro\%20Blanco.pdf

Gutiérrez, M. E., y Romero, F. (2015). Valoración del daño ambiental en la cuenca del río Sonora, asociado al derrame del 6 de agosto de la mina Buenavista del Cobre. En Memorias. XXXI Convención Internacional de Minería. Acapulco: Asociación de Ingenieros de Minas, Metalurgistas y Geólogos de México, A. C.

Ibarra, M. F., y Moreno, J. L. (2017). La justicia ambiental en el río Sonora. RevIISE-Revista de Ciencias Sociales y Humanas, 10(10), 135-155. Recuperado de https://www.redalyc.org/jatsRepo/5535/553559586012/html/index. html

Instituto Nacional de Estadística y Geografía (INEGI). (2010). Red hidrográfica escala 1:50,000. Recuperado de https: / / www.inegi.org. mx/temas/hidrografia/

Instituto Nacional de Estadística y Geografía (INEGI). (2020). Censo de Población y Vivienda 2020. Recuperado de https://inegi.org.mx/programas/ccpv/2020/\#Tabulados

Laboratorio Nacional de Geoquímica y Mineralogía (LANGEM). (2016). Evaluación del riesgo a la salud humana por exposición a elementos potencialmente tóxicos en suelos, asociados al derrame de Buenavista del Cobre ocurrido en agosto de 2014. Universidad Nacional Autónoma de México, Universidad de Sonora, Instituto Tecnológico de Sonora. Recuperado de http://www. fideicomisoriosonora.gob.mx/docs/Estudios\%20y\%20Proyectos/ANEXO\%20 $1.10 \% 20(1) . p d f$

Luque, D., y Murphy, A. (2020). La gramática del río Sonora que exhibió el derrame de la mina Cananea. Argumentos. Estudios Críticos de la Sociedad (33), 217-240. Recuperado de https://argumentos.xoc.uam.mx/index.php/ argumentos/article/view/1134

Luque, D., Murphy, A., Jones, E., Burquez, A., Martínez, A., Manrique, T., y Esquer, D. (2019). Río Sonora: el derrame de la mina Buenavista del Cobre-Cananea, 2014. Hermosillo: Centro de Investigación en Alimentación y Desarrollo, A. C.

Montero-Contreras, D. (2006). El agua embotellada en América del Norte: un negocio jugoso en pocas empresas. Denarius. Revista de Economía y Administración, 12(1), 189-220.

Montero-Contreras, D. (2016). El consumo de agua embotellada en la Ciudad de México desde una perspectiva institucional. Agua y Territorio (7), 35-49. doi: https: / / doi.org/10.17561/at.v0i7.2961

Morgan, D. (1998). Practical strategies for combining qualitative and quantitative methods: applications to health research. Qualitative Health Research, 8(3), 362-376. doi: https://doi.org/10.1177/104973239800800307

Pacheco-Vega, R. (2015). Agua embotellada en México: de la privatización del suministro a la mercantilización de los recursos hídricos. Espiral. Estudios 
sobre Estado y Sociedad, 22(63), 221-263. doi: https://doi.org/10.32870/ espiral.v22i63.1671

Pacheco-Vega, R. (2017). Agua embotellada en Mexico: realidades, retos y perspectivas. En C. López, L. Zambrano, R. Ruiz, M. Guzmán, R. Pérez, R. Sandoval y A. Caldera-Ortega (eds.), El agua en México: actores, sectores y paradigmas para una transformación social-ecológica (pp. 195-214). Ciudad de México: Friedrich Ebert Stiftung.

Pacheco-Vega, R. (2019a). (Re)theorizing the politics of bottled water: water insecurity in the context of weak regulatory regimes. Water (Switzerland), 11(4). doi: https://doi.org/10.3390/w11040658

Pacheco-Vega, R. (2019b). Human right to water and bottled water consumption: governing at the intersection of water justice, rights and ethics. En F. Sultana y A. Loftus (eds.), Water Politics: Governance, Justice and the Right to Water (pp. 113-128). Londres: Routledge. doi: https://doi. org/10.4324/9780429453571-9

Priego, K., y Soares, D. (2017). Agua y dimensión de género. Recuperado de https: / /agua.org.mx/biblioteca/agua-y-dimension-de-genero-sp-13769/

Programa de Naciones Unidas para el Desarrollo (PNUD). (2006). Más allá de la escasez: poder, pobreza y crisis mundial del agua. Informe sobre desarrollo humano 2006. Recuperado de http://hdr.undp.org/sites/default/files/ hdr_2006_es_completo.pdf

Red de Género y Medio Ambiente (REGEMA). (2006). La agenda azul de las mujeres. Ciudad de México: Instituto Mexicano de Tecnología del Agua (IMTA), SEMARNAT y PNUD.

Rocheleau, D., Thomas-Slayter, B., y Wangari, E. (eds.). (1996). Gender and environment. A feminist political ecology perspective. En D. Rocheleau, B. Thomas-Slayter y E. Wangari (eds.), Feminist Political Ecology: Global Issues and Local Experiences (pp. 3-26). Nueva York: Routledge.

Rodríguez-Heredia, D. (2017). Intoxicación ocupacional por metales pesados. Medisan, 21(12), 3372-3385. Recuperado de http://scielo.sld.cu/scielo. php?script=sci_arttext\&pid=S1029-30192017001200012

Romero-Lázaro, E., Ramos-Pérez, D., Romero, F., y Sedov, S. (2019). Indicadores indirectos de contaminación residual en suelos y sedimentos de la cuenca del río Sonora, México. Revista Internacional de Contaminacion Ambiental, 35(2), 371-386. doi: https:// doi.org/10.20937/RICA.2019.35.02.09

Salazar, H., y Rodríguez, M. (2015). Miradas en el territorio, cómo mujeres y hombres enfrentan la minería. Aproximaciones a tres comunidades mineras en México. Ciudad de México: Fundación Heinrich Böll Stiftung.

Sariego, J. L. (2010). De minas, mineros, territorios y protestas sociales en México: los nuevos retos de la globalización. Cahiers des Amériques Latines 60-61, 173-192. doi: https://doi.org/10.4000/cal.1435

Secretaría de Medio Ambiente y Recursos Naturales (SEMARNAT). (2018). Informe de acciones. Fideicomiso Río Sonora. Ciudad de México. Recuperado de https: / / www.gob.mx/semarnat/acciones-y-programas/informe-de-acciones 
Sistema Nacional de Información del Agua (SINA). (2015). Cobertura universal. Recuperado de http://sina.conagua.gob.mx/sina/index.php?p=9\#: :text=La\%20cobertura\%20de\%20agua\%20potable,0\%20bien\%20de\%20otra\%20 vivienda

Soares, D. (2007). Acceso, abasto y control del agua en una comunidad indígena chamula en Chiapas. Un análisis a través de la perspectiva de género, ambiente y desarrollo. región y sociedad, 19(38), 25-50. doi: https://doi. org/10.22198/rys.2007.38.a556

Toscana, A., y Hernández, P. de J. (2017). Gestión de riesgos y desastres socioambientales. El caso de la mina Buenavista del Cobre de Cananea. Investigaciones Geograficas, (93), 1-14. Recuperado de http://www.investigacionesgeograficas.unam.mx/index.php/rig/article/view/54770/52666

Vázquez, V. (2008). Clase, etnia, género y agua. El sistema Cutzamala y el movimiento mazahua en defensa del agua. En D. Soares, S. Vargas y M. R. Nuño (eds.), La gestión de los recursos hidricos: realidades y perspectivas, Vol. 1 (pp. 283-309). Jiutepec: Instituto Mexicano de Tecnología del Agua.

Vázquez, V., y Sosa, D. M. (2017). Sin agua no vivo. Género y derecho humano al agua en el municipio de La Antigua, Veracruz. Agricultura, Sociedad y Desarrollo, 14(3), 405-425. Recuperado de http://www.scielo.org.mx/scielo. php?script=sci_arttext\&pid=S1870-54722017000300405

Vega-Amaya, M. (2020). ¿Agua segura? El mercado de agua embotellada en Hermosillo. Hermosillo: El Colegio de Sonora. 